\title{
QUE TAL UMA PAUSA PARA UM "CAFÉ CULTURAL"? INTERCULTURALIDADE E (TRANS) FORMAÇÕES DE IDENTIDADES DE PROFESSORES DE LÍNGUAS
}

\author{
What about a "cultural coffee break? Interculturality and language \\ teachers' identity (trans) formations
}

\author{
Angela Maria Hoffmann WALESKO \\ Universidade Federal do Paraná \\ angela.walesko@ufpr.br \\ https://orcid.org/0000-0001-7234-3350 \\ Catarina PORTINHO-NAUIACK \\ Universidade Federal do Paraná \\ catarinaportinho@ufpr.br \\ https://orcid.org/0000-0002-9473-1570
}

\begin{abstract}
RESUMO: Este artigo objetiva discutir (trans)formações identitárias de professores de línguas a partir de interações interculturais vivenciadas com falantes nativos de contextos culturais diversos. Para isso, tem como recorte experiências entre professores de inglês em formação inicial e falantes nativos dessa língua durante as edições de 2017 a 2020 do evento de extensão "Café Cultural" na Universidade Federal do Paraná (UFPR), em Curitiba (Paraná). Este estudo, qualitativo e de cunho etnográfico, relaciona esse cenário empírico a concepções teóricas bakhtinianas de língua como discurso e prática social, de ensino-aprendizagem de Inglês como Língua Franca (ILF) e o mito do "falante-nativo", bem como de interculturalidade e translinguismo e de crenças e identidades docentes. Apresenta, como resultados iniciais, nossas percepções, como professoras-formadoras, sobre como determinadas interações no evento quebraram estereótipos e desmistificaram crenças, formando e transformando o modo como os professores participantes concebiam a língua inglesa e seus falantes nativos e como se identificavam enquanto docentes de inglês. $\mathrm{O}$ estudo ressalta, ainda, a importância da promoção de oportunidades de diálogo intercultural entre professores em formação e falantes nativos em busca da legitimação de linguascultura diversas em prol de uma educação em línguas cada vez mais ética e cidadã. PALAVRAS-CHAVE: Café Cultural; identidades de professores de línguas; interculturalidade; falante nativo.
\end{abstract}

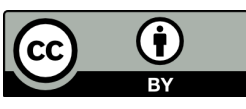




\begin{abstract}
This article aims at discussing language teachers identity (trans)formations from intercultural interactions with native speakers from diverse cultural contexts. For this purpose, it is based on experiences among pre-service English teachers and English native speakers carried out along the 2017-2020 editions of the event entitled "Café Cultural", at the Federal University of Paraná (UFPR), in Curitiba (Paraná). This qualitative and ethnographic study relates this empirical scenario and theoretical bakhtinian conceptions of language as discourse and social practice, of English as a Lingua Franca (ELF) and the "native speaker" myth, as well as of interculturality, of translingualism and of teacher beliefs and identities. It presents, as initial results, our perceptions as teacher educators on how specific interactions performed during the event have broken stereotypes and demystified beliefs, forming and transforming the way the participant teachers understood the English language and its native speakers, including how they identified themselves as English teachers. Furthermore, the study emphasizes the relevance of the promotion of intercultural dialog opportunities among pre-service teachers and native speakers for the legitimation of different linguacultures in favor of an increasingly ethical and citizenship languages education. KEYWORDS: Cultural Coffee Break; language teachers identity; interculturality; native speakers.
\end{abstract}

\title{
INTRODUÇÃO
}

O verbo comer, em português, origina-se do latim comedere, que pode ser traduzido como tomar os alimentos em companhia, pois é a junção do verbo edere, que significa ingerir alimentos, com o prefixo com, que significa em comum, comunitário. Pode-se então dizer que, em português, o verbo comer apresenta uma indicação etimológica, que para leigos em filologia românica pode passar desapercebida, para o sentido comunitário do ato de alimentar-se.

Contudo, muito antes de almejar filosofar sobre aspectos linguísticos, a humanidade partilha o alimento, seja no seio da unidade familiar seja em rituais ou festas comunitárias. Segundo Carneiro (2003, p. 204), “o próprio homem modifica o sentido do consumo alimentar, dando-lhe um significado cultural, ao fazer dos rituais de alimentação uma maneira de se relacionar socialmente". Transcendendo, portanto, características biológicas ligadas à sobrevivência, as práticas alimentares envolvem inúmeros significados sociais e também emocionais, uma vez que promovem a afetividade por meio da possibilidade da interação entre as pessoas, a construção de saberes, costumes e crenças individuais e coletivas que, por sua vez, formam e transformam nossas 
identidades. Considerando tais perspectivas e com o propósito de estreitar os laços afetivos entre os integrantes ${ }^{1}$ dos cursos de línguas ofertados ao longo dos últimos anos (2009-2020) no projeto de extensão "Formação em Línguas para Fins Acadêmicos"2 (IFA), hoje renomeado "Formação em Idiomas para Vida Universitária" (FIVU), do Setor de Educação da Universidade Federal do Paraná (UFPR), criou-se a prática de uma pausa para o café nos intervalos das aulas que aconteceram, predominantemente, nas manhãs de sábado. Essa cultura, aliás, vai muito além da tradição brasileira de se tomar um "cafezinho" - estimulada ao longo dos últimos três séculos ${ }^{3}$, quando do surgimento da cafeicultura no Brasil: trata-se de uma pausa garantida pelos direitos trabalhistas e que, com os comprovados benefícios da cafeína para a saúde, tais como a melhora da memória e da concentração ${ }^{4}$ e, por consequência, o aumento da produtividade, acaba tendo o café como produto de consumo mais do que incentivado. Tais atributos também são, muito provavelmente, os responsáveis pelo valor dado a um bom cafezinho nas instituições de ensino brasileiras, em especial nos intervalos entre aulas, acompanhado ou não de lanches variados e de boas conversas entre as pessoas que o compartilham.

Durante os primeiros anos do projeto, a pausa para o café era organizada de maneira espontânea e por curso/idioma, em sala de aula, pelos professores-praticantes ${ }^{5} \mathrm{e}$ professores-formadores, juntamente com os alunos. A partir de 2016, essa atividade foi organizada pelos coordenadores com professores-praticantes e graduandos/as bolsistas ${ }^{6}$ como uma estratégia para unir integrantes das diferentes línguas dos cursos ofertados em um momento de compartilhamento, não somente do café e das delícias que uma dupla ou trio responsável trazia a cada sábado, mas, principalmente de ideias, de práticas docentes, de "boas novas" e também de notícias nem sempre "tão boas", ou seja, da vida na

\footnotetext{
${ }^{1}$ Professores-formadores do Departamento de Teoria e Prática de Ensino (DTPEN), que atuam como coordenadores de cursos de inglês, espanhol, francês, italiano, alemão e japonês; professorespraticantes, licenciandos/as em Letras e corpo discente de cursos diversos de graduação e pósgraduação da Universidade Federal do Paraná (UFPR).

${ }^{2}$ Como o projeto foi ficando cada vez mais conhecido, os alunos em geral passaram a chamá-lo de Idiomas para Fins Acadêmicos (IFA), já que o nome oficial (Formação em Línguas para Fins Acadêmicos) era muito longo. Esse nome fantasia - IFA — passou a fazer parte da identidade do projeto.

3 “As raízes do café no Brasil foram plantadas no século XVIII, quando as mudas da planta foram cultivadas pela primeira vez, que se tem notícia, por Francisco de Melo Palheta, em 1727, no Pará." (PINTO, 2020).

${ }^{4}$ Leia mais em Revista Veja Saúde. Os beneficios do café para a sua saúde. 8 jun. 2018. Disponível em: https://saude.abril.com.br/alimentacao/os-beneficios-do-cafe-para-a-sua-saude/. Acesso em: 10 fev. 2021.

${ }^{5}$ Professores-praticantes: alunos licenciandos de Letras em período de estágio.

${ }^{6} \mathrm{O}$ projeto foi contemplado com diferentes modalidades de bolsas ao longo de sua existência.

Revista X, v. 16, n. 4, p. 1120-1142, 2021. 
universidade e fora dela, como parte essencial do processo de formação dos licenciandos e dos formadores, enquanto professores em formação, e também como indivíduos.

O bom e velho cafezinho era também a personagem principal de uma atividade interativa promovida pelos cursos de espanhol, chamada "Café Cultural", que acontecia uma vez ao semestre. Em uma manhã de aula, ou em parte dela, a pausa para o café acontecia nesses cursos como um espaço de interação não apenas entre os professorespraticantes de espanhol e seus coordenadores, mas também desses e dos alunos dos cursos com falantes nativos da língua, convidados a participarem de uma roda de conversa, que acontecia em língua espanhola, sobre assuntos de interesse das turmas.

A interação e troca de ideias durante as pausas para o café do grupo de professores - formadores e praticantes das línguas diversas - oportunizou que os professores e coordenadores de espanhol compartilhassem essa atividade com os demais colegas e daí originou-se a ideia de um grande evento intercultural do projeto, a ser realizado com todos os alunos de todos os cursos das seis línguas ofertadas ${ }^{7}$, com a interação com falantes dessas línguas (como língua materna ou segunda língua), convidados a participarem do evento e a apreciarem um café tipicamente brasileiro, acompanhado de delícias nacionais variadas e de boas conversas. Surge assim, em 2017, o primeiro evento de extensão "Café Cultural" do projeto IFA, da UFPR, cenário para as discussões sobre interculturalidade e (trans)formações ${ }^{8}$ identitárias de professores de línguas, foco deste artigo.

Tais discussões partem, empiricamente, de nossas percepções pessoais, enquanto professoras-formadoras e coordenadoras tanto da área de línguas anglo-germânicas no projeto quanto de algumas edições do evento, sobre algumas experiências de interação entre brasileiros e estrangeiros ao longo de atividades, por nós vivenciadas, promovidas pelos professores-praticantes dos cursos de inglês que fizeram parte dos eventos presenciais "Café Cultural” entre os anos de 2017 e 2019 e do evento online de 2020 do curso de Inglês — Módulo 2/2020, intitulado "Intercultural Cafe"". Essas discussões, sobre interculturalidade e identidades docentes, têm como embasamento

\footnotetext{
${ }^{7}$ Inglês, espanhol, francês, alemão, italiano e japonês.

8 Utilizamos (trans)formações considerando que os indivíduos, na interação social, se formam e também se transformam, ou seja, aprendem novos conceitos teórico-práticos e também mudam antigos.

${ }^{9}$ Em 2020, o evento foi realizado na modalidade remota por conta da suspensão das atividades educacionais presenciais no Brasil e em outros países, devido à pandemia Covid-19; como o evento, naquele momento, restringiu-se à área de língua inglesa, foi intitulado "Intercultural Café", que, em inglês, pareceu, para os envolvidos na sua organização, soar e melhor remeter à inter/ação entre falantes de inglês de contextos culturais diferentes (embora dentro dos mesmos países - Brasil e Estados Unidos da América).
} 
teórico principal concepções do Círculo de Bakhtin (2017) de língua como discurso e prática social, leituras sobre ensino-aprendizagem de Inglês como Língua Franca (ILF) ou, em inglês, English as a Lingua Franca (ELF) e o mito do "falante nativo"10 (LIU, 1999; HOLLIDAY, 2006; PENNYCOOK, 2004, 2007; GIMENEZ; CALVO; EL KADRI, 2011; JENKINS, 2015; JORDÃO, 2010, 2014; JORDÃO; MARQUES 2017; WALESKO, 2019), sobre interculturalidade (WALESKO, 2006; CANAGARAJAH, 2014a; KUMARAVADIVELU, 2012; PICANÇO, 2012), sobre translinguismo (GARCIA; WEI, 2014; CANAGARAJAH, 2013, 2017; LEE, 2018) e sobre crenças e identidades docentes (BARCELOS, 2004, 2006, 2008; RAJAGOPALAN, 2005; BERNAT, 2008; KRAMSCH, 2012; CANAGARAJAH, 2014b; RICHARDSON, 2016; SIQUEIRA, 2017; ZACCHI, 2017).

Temos como objetivo principal, neste texto, apresentar o quanto a interação com falantes nativos de língua inglesa, originários de contextos culturais diversos, durante as edições do evento "Café Cultural" impactou a visão de professores em formação sobre o inglês que aprendem e ensinam e sobre suas identidades pessoais e profissionais enquanto discentes e docentes da língua no Brasil. Para isso, acreditamos que seja importante apresentar, primeiramente, as informações mais relevantes sobre a organização e realização da proposta do evento ao longo dos últimos quatro anos, tanto na modalidade presencial quanto na remota, de modo a contextualizar o leitor e facilitar a compreensão das discussões teóricas sobre interculturalidade e (trans)formações identitárias de professores.

$\mathrm{Na}$ sequência, apresentamos relações sobre crenças de professores de inglês em modelos de língua inglesa, provenientes de falantes tidos como provedores de normas na língua (os míticos "falantes nativos"), e suas identidades docentes, bem como o impacto dessas construções identitárias em suas práticas pedagógicas. Em seguida, relatamos nossas percepções pessoais sobre certas experiências de interação no evento "Café Cultural", entre professores-praticantes e falantes nativos de inglês, que impactaram esses professores na medida em que quebraram estereótipos e desmistificaram crenças, formando e transformando o modo como se identificavam como docentes de inglês. Concebemos essas percepções como resultados positivos do evento enquanto uma ação de formação docente. Como considerações finais, ressaltamos a importância de

\footnotetext{
${ }^{10}$ As aspas são utilizadas ao mencionar "falante/s nativo/s" como sinônimo de mito ou modelo de competência linguística e cultural seguindo a linha de pensamento de alguns teóricos que questionam a existência real desse/s falante/s ideal/ais em qualquer língua; o termo falante/s nativo/s, sem aspas, empregado em alguns trechos do texto, refere-se ao/s indivíduo/s com uma ou mais línguas maternas (língua/s não aprendidas como adicional/nais ou estrangeira/s).
} 
considerarmos e promovermos, em prol da legitimação de linguascultura ${ }^{11}$ diversas e da quebra de estereótipos e formação docente ética e cidadã, oportunidades de diálogo intercultural entre professores de línguas e falantes originários de contextos diversos, como as que foram promovidas ao longo das edições do evento de extensão "Café Cultural" do projeto IFA/FIVU.

\section{A PAUSA PARA O "CAFÉ CULTURAL": ORGANIZAÇÃO E REALIZAÇÃO}

Ao longo dos últimos quatro anos (2017-2020) promoveu-se, por meio do evento de extensão "Café Cultural", uma pausa nas atividades letivas rotineiras, próxima ao encerramento dos cursos de línguas ofertados pelo projeto de extensão universitária IFA/FIVU. O evento foi, em todas as suas edições, registrado junto ao Departamento de Teoria e Prática de Ensino (DTPEN), do Setor de Educação da UFPR, sediado na cidade de Curitiba (Paraná) por dois dos professores-formadores dos cursos ofertados a cada período (coordenador e vice coordenador) e organizado por esses e os demais professores-formadores/coordenadores e professores-praticantes. Entre 2017 e 2019, os organizadores contaram com a parceria da coordenação e de professores atuantes nos cursos de Português como Língua Estrangeira (PLE) do Centro de Línguas e Interculturalidade (CELIN) da UFPR ${ }^{12}$, que convidavam seus alunos estrangeiros, falantes das línguas inglesa, espanhola, francesa, italiana, alemã e japonesa, como língua materna ou segunda língua, para participarem do evento como ministrantes. Também participaram de algumas edições do evento alunos estrangeiros intercambistas de graduação e pós-graduação e English Teaching Assistants (ETAs) ${ }^{13}$ do Programa Idiomas sem Fronteiras da UFPR, intercambistas na UFPR e seus colegas também ETAs, por eles convidados, intercambistas em outras universidades na cidade de Curitiba. A eles cabia a presença no dia do evento (uma manhã de sábado letivo dos cursos de línguas ofertados pelo IFA/FIVU) para a interação em rodas de conversa orientadas pelos professorespraticantes, também ministrantes. O registro formal do evento como evento de extensão universitária garantia, tanto para coordenadores quanto para ministrantes e demais participantes, certificação emitida pela Pró-Reitoria de Extensão e Cultura (PROEC)

\footnotetext{
${ }^{11}$ Empregamos o termo linguacultura neste texto considerando o conceito de inseparabilidade entre língua e cultura.

${ }^{12}$ Em 2020, devido à pandemia Covid-19, o CELIN-UFPR suspendeu suas atividades letivas e, por isso, não houve parceria entre o projeto FIVU e o PLE para a realização do evento.

${ }^{13}$ ETAs: English teaching assistants (Assistentes de ensino de inglês). Para maiores informações sobre o programa ETAs, acesse: https://fulbright.org.br/awards-for-us-citizens/english-teachingassistantship-eta/.
}

Revista X, v. 16, n. 4, p. 1120-1142, 2021. 
da UFPR. A participação no evento era facultativa, cabendo aos coordenadores de cada curso averiguar, junto aos professores-praticantes e alunos, o interesse a cada edição. Os professores-ministrantes e professores-praticantes eram responsáveis por orientar e preparar os alunos para as rodas de conversa com os convidados estrangeiros por meio do levantamento de temas e formulação de perguntas que norteassem a conversa, que tinha a duração de cerca de uma hora e 30 minutos.

\section{As rodas de conversa}

Para o evento "Café Cultural" do projeto IFA/FIVU a coordenação de cada curso reservava, previamente, uma sala ampla onde alunos e professores-praticantes dos diferentes cursos de um mesmo idioma pudessem receber os convidados estrangeiros para uma roda de conversa acerca de temas relacionados à vida universitária e ao cotidiano dessas pessoas em seus países de origem, geralmente tecendo paralelos com a realidade de onde viviam naquele momento.

Os falantes nativos participantes eram convidados a se apresentar e tinham a liberdade de mostrar, em apresentação em tela com o uso da internet ou de um dispositivo usb (pen-drive), fotos ou vídeos sobre sua terra natal e/ou universidade de origem. Durante a conversa com a turma, eles respondiam perguntas sobre temas de interesse dos participantes e também perguntavam sobre o Brasil e a cidade de Curitiba, promovendo comparações reflexivas para os que ali se encontravam e oportunizando o uso da línguaalvo estudada. Em cursos que recebiam muitos estrangeiros, como sempre foi o caso dos cursos de inglês, buscou-se organizar grupos menores ou pequenas rodas de conversa e os professores-praticantes estabeleciam de dez a vinte minutos para temas específicos, como educação, saúde, lazer, estudos na universidade etc. Transcorrido o tempo estabelecido previamente, os convidados estrangeiros saíam do grupo onde estavam para unir-se a um novo grupo até que todos os temas e todos os grupos fossem contemplados. Através de nossa observação in loco, percebemos que, quando a conversa era realizada em grupos menores, proporcionava uma participação mais equânime entre os membros do grupo, já que a exposição, ao falar inglês, era proporcional à quantidade de participantes e os participantes se sentiam muito mais confortáveis para perguntar e responder questões do que em um grande grupo.

Para o evento na modalidade remota, em 2020, utilizou-se a plataforma Teams institucional da UFPR e, após uma abertura geral de boas-vindas e de orientações para o evento e apresentação oral de cada um dos quatro falantes nativos de inglês, foram organizados subgrupos nos quais um dos estrangeiros, dois professores-praticantes Revista X, v. 16, n. 4, p. 1120-1142, 2021. 
e alunos do curso de inglês remoto conversariam tendo como assunto um dos temas tradicionalmente propostos para as edições presenciais mas, dessa vez, relacionando tal tema ao momento da pandemia Covid-19 nos contextos culturais locais em que estavam inseridos. Os falantes nativos convidados trocavam de grupo na medida em que os temas eram substituídos por outros, sempre orientados e "virtualmente acompanhados" por um dos professores-praticantes, com o qual poderiam se comunicar inclusive via mensagens de Whatsapp a fim de sanar quaisquer dúvidas ou problemas.

\section{O café Tandem}

Ao redor de uma grande mesa comunitária, os integrantes das línguas participantes de cada edição presencial do evento reuniam-se, após a roda de conversa, com os convidados estrangeiros para um delicioso café, oferecido pelos organizadores e alunos dos cursos, com comidas típicas brasileiras, que incluíam várias garrafas térmicas de café, identificadas com um rótulo da saborosa e tradicional bebida brasileira nas línguas estudadas no curso: coffee, kaffee, caffè, café, カフェ, café. Essa atividade do evento durava cerca de uma hora e caracterizava-se como uma excelente oportunidade de "Tandem"14, já que todos os participantes (brasileiros e estrangeiros) comunicavam-se intercalando suas respectivas línguas maternas com as línguas-alvo para praticar idiomas, conhecendo pessoas e fazendo novas amizades. Por isso, chamamos esse momento de café Tandem.

A cada nova edição do "Café Cultural", aumentava consideravelmente o número de participantes. Em algumas edições, circularam mais de 100 participantes que, em pequenos grupos, buscavam se conhecer e interagir nas línguas que conheciam, e, muitas vezes, também nas que não conheciam, utilizando, para isso, recursos semióticos outros que não a palavra falada em suas práticas translíngues (CANAGARAJAH, 2013) e interculturais, muito comuns em interações entre falantes multilíngues em zonas de contato $^{15}$. Canagarajah explica:

Compreendemos mais línguas do que falamos. Usando nossas habilidades receptivas podemos entender a língua do/a interlocutor/a,

\footnotetext{
${ }^{14}$ Tandem: programa do CELIN-UFPR de integração (em encontros agendados pelo programa) entre pessoas de diferentes culturas que queiram aprimorar seus conhecimentos em duas línguas estrangeiras distintas. Para maiores informações consulte: http://www.celin.ufpr.br/index.php/oque-e-tandem. Acesso em: 3 maio 2021.

${ }^{15}$ Zonas de contato: regiões de fronteira entre países onde há contato entre falantes de diferentes línguas.
}

Revista X, v. 16, n. 4, p. 1120-1142, 2021. 
da mesma forma que o/a interlocutor/a usa sua competência para entender sua própria língua. E a conversa continua. Além disso, a comunicação envolve mais do que palavras. Em muitos casos, os falantes usam o contexto, gestos, e objetos no cenário para interpretar as colocações do/a interlocutor/a. ${ }^{16}$ (CANAGARAJAH, 2013, p. 5, tradução nossa).

A efervescência das trocas e diálogos multi e translingues acontecia diante de nossos olhos, de tal modo que, em determinado momento, sentimos a necessidade de facilitar e incentivar o diálogo entre indivíduos tão diversos. Para aproximar as pessoas com interesses linguísticos correspondentes nesse grande encontro, foram desenvolvidos pequenos adesivos (que eram fixados na roupa do participante em local visível) para a identificação dos idiomas falados ou estudados, assim como a respectiva fluência, através de sinal ou sinais de,+++ ou +- , como ilustrado a seguir:

Figura 1: Sinais de identificação da fluência.

\begin{tabular}{|l|l|l|l|}
\hline PORTUGUÊS $(+-)$ & ENGLISH $(++)$ & DEUTSCH $(+)$ & FRANÇAIS $(+)$ \\
\hline
\end{tabular}

Fonte: as autoras.

O sinal ++ significava muita fluência na língua, ou língua materna, enquanto o + uma boa fluência; +- indicava um nível regular de proficiência na língua. O emprego desses adesivos serviu, por exemplo, para aproximar pessoas que, porventura, ainda não se sentiam totalmente confiantes para iniciar uma conversa com alguém desconhecido em uma língua estrangeira. Também foi um breve momento de autoavaliação da biografia linguística de cada participante, uma vez que ele/a era a pessoa responsável por identificar qual nível de fluência era o mais indicado para si. Na formação dos professores-praticantes envolvidos nas atividades de inglês, nas aulas do curso de Letras, também refletimos, a partir da observação desse momento no evento "Café Cultural", sobre como as pessoas se identificam quanto à sua fluência na língua estrangeira que estudam, concluindo que geralmente pela oralidade, de acordo com o quanto conseguem comunicar-se com outras pessoas, independente se nativos ou não.

\footnotetext{
${ }^{16}$ No original: "We understand more languages than we can speak. Using our receptive skills we can understand the interlocutor's language, in the same way that the interlocutor uses his/ her competence to understand our own language. And the conversation proceeds. Besides, communication involves more than words. In many cases, speakers use the context, gestures, and objects in the setting to interpret the interlocutor's utterances.".
} 


\section{A CRENÇA NO MITO DO "FALANTE NATIVO" E AS IDENTIDADES E PRÁTI- CAS DOCENTES DE PROFESSORES DE LÍNGUAS}

Se o evento "Café Cultural" promove a interação entre professores de línguas em formação inicial e falantes nativos dessas línguas, torna-se muito importante discutir os impactos da crença em "falantes nativos" imaginados, irreais (que talvez poderiam imaginariamente corresponder a alguns dos convidados estrangeiros participantes no evento) nas identidades desses professores e, por sua vez, em suas práticas docentes. Para isso, partimos da discussão sobre a origem dessa crença, que surge junto ao tradicional conceito de língua como sistema de normas fixo e monológico, conceito esse que norteia a noção de língua-nativa e/ou língua-nação pressupondo que as identidades nacionais (ou, em alguns casos, locais) sejam herdadas e fixas, e que se contrapõe ao conceito bakhtiniano de língua como discurso, como prática social constitutiva dos sujeitos e por eles constituída nas relações dialógicas. Portanto,

[s]endo impossível separar língua de ideologia, de cultura e das intenções dos falantes que a utilizam em suas interações sociais - interações que diferem de acordo com a situação, o momento e com os interlocutores, mesmo dentro da mesma nação, interferindo diretamente no uso da língua/linguagem - e, considerando-se língua como discurso, é também impossível afirmar que existam línguas nativas (padrão, de determinado local ou nação) e línguas a elas estrangeiras. (WALESKO, 2019, p. 100).

Como prática social, uma língua não pode ser separada de cultura, ou seja, caracteriza-se como uma linguacultura, entendendo-se cultura não apenas no sentido superficial de costumes ou artefatos de um determinado local, mas sim como inerente aos indivíduos: suas ideias, valores, opiniões, sentimentos, questionamentos, crenças etc., conscientes ou não, nos contextos em que vivem e em constante transformação, que os tornam sujeitos culturais e interculturais à medida em que interagem com outros contextos diversos. Ou seja,

[o] mundo que construímos, as relações que estabelecemos nos contextos que criamos e dos quais participamos de forma intensa, participativa ou omissa nos tornam sujeitos culturais criativos e construtores da nossa própria cultura. Cada pessoa se constitui como ser humano à medida que apreende $\mathrm{a}(\mathrm{s})$ cultura(s) que constituem $\mathrm{e}$ atravessam o contexto social em que vive. Ao interagir com outras culturas, o sujeito coloca em questão padrões culturais próprios, o que 
pode promover processos de aprendizagem pessoal e de transformação sociocultural. (WALESKO, 2006, p. 27).

Nos construtos sociais língua nativa e língua-nação, entendidos como sistema linguístico fixo e padrão de um determinado país, a noção de cultura poderia ser ensinada, segundo Kramsch (1996, p. 7), sob duas perspectivas: "cultura na língua”, que pressupõe o ensino de aspectos culturais de determinados países, simultaneamente ao trabalho com a aquisição da língua, e "cultura e língua", em que tais aspectos culturais são ensinados paralelamente ao ensino de estruturas e vocabulário na LE. Nenhuma dessas "metodologias" promoveria qualquer tipo de reflexão crítica e/ou intercultural por parte do aprendiz sobre a língua-alvo e a/as língua/s que domina ou conhece, seja/m materna/s ou não. Atrelada a esse construto social irreal, mítico, de língua nativa e língua-nação está o conceito de "falante nativo", também um mito usado para "criar e sustentar uma identidade nacional" (BUTCHER, 2005, p. 20).

A área de ensino-aprendizagem de línguas sempre teve "falantes nativos" ideais, originários de países ou de cidades em determinados países com prestígio político, social e econômico em termos globais, como modelos criados para serem seguidos, como se de fato existissem e representassem toda a língua e cultura de uma nação ou localidade dentro de uma nação. Esses míticos "falantes nativos", inseridos em especial no chamado Norte-global ${ }^{17}$, seriam, portanto, criadores e provedores de normas para os que aprendem "sua língua" como língua estrangeira (no sentido literal, enquanto "donos da língua") e, junto a ela, seu modo de pensar e agir - sua cultura, sempre como superior a outras. Assim, encontramos, ao longo da história, metodologias e materiais didáticos para o ensino-aprendizagem de línguas que trazem o "espanhol da Espanha ou da Argentina", "o inglês britânico ou o americano", o "francês de Paris", o "alemão de Berlim" ou o português "brasileiro, do Rio de Janeiro", por exemplo, como línguas padrão, com seus imaginados "falantes nativos". Tão estereotipadamente imaginados que, obviamente, não incluem cidadãos, desses mesmos países ou cidades, com baixo nível educacional e socioeconômico, nem, em muitos casos, cidadãos negros ou discriminados por questões de religião e/ou gênero, uma vez que não seria lucrativo para a indústria do ensino-aprendizagem de línguas estrangeiras vender imagens de sujeitos culturais "não interessantes" para um público que, muitas vezes, busca aprender uma outra língua para

\footnotetext{
${ }^{17}$ Norte-global e Sul-global são termos utilizados em estudos pós-coloniais e transnacionais para referir-se ao conjunto de países considerados desenvolvidos e em desenvolvimento, respectivamente que substituem os termos primeiro e terceiro mundo. O Sul-global também pode incluir regiões mais pobres de países do Norte-global.
} 
aproximar-se de uma suposta cultura daquela língua. Portanto, não basta ter nascido em um local de prestígio sociocultural para ser considerado "o falante nativo", modelo ideal para o ensino-aprendizagem de línguas, contrariando o conceito de nativo como "nascido", como explica Cook:

O elemento indiscutível na definição de falante nativo é que uma pessoa é um falante nativo da língua que aprendeu primeiro; as outras características são incidentais, descrevendo quão bem um indivíduo usa a língua. Alguém que não aprendeu uma língua na infância não pode ser um falante nativo da língua. (COOK, 1999, p. 187).

Entretanto pesquisas como a de Rajagopalan (2005) nos mostram que seria necessário "reprogramar" gerações de professores que cresceram acreditando que a fluência "nativa" é uma questão de local de nascimento e terem, como seu maior objetivo, "ser tão proficiente na língua a ponto de ser aceito na comunidade de falantes nativos como membros 'comuns'." (RAJAGOPALAN, 2005, p. 295)

Portanto a crença de professores de línguas em modelos de "falantes nativos" a serem copiados traz, para suas práticas docentes, apenas impactos negativos: sentimentos de fracasso, incompetência ou de inferioridade ao não conseguirem compreender ou se comunicar a/na língua que ensinam, relacionados à chamada "Síndrome do Impostor" (BERNAT, 2008; KRAMSCH, 2012). Ou seja, crenças como essa, que formam suas identidades, pessoais e profissionais, os definem pelo que não são: "não nativos" e, por consequência, "não proficientes" ou "não ideais" para o ensino de uma língua que não seja sua língua materna. Porém, segundo Walesko (2019, p. 119), é possível "adquirir uma posição mais positiva e menos discriminatória, em consonância com as perspectivas pós-modernas das teorias sobre multilinguismo e translinguismo", em especial na área de formação docente. Concordamos com Richardson (2016) quando afirma que o termo "não nativo" não deveria mais ser empregado nas referências a professores de línguas que não são sua língua materna. As justificativas para a preferência por professores nativos ou com a proficiência de um nativo não podem mais se manter já que, como indivíduos multilíngues, são multicompetentes nas línguas que ensinam, sendo essas modificadas por seus usuários, nos contextos culturais em que estão inseridos e não a língua-nativa, pertencente a determinada cultura, supostamente imutável.

Acreditamos que o evento "Café Cultural", ao promover interações entre os professores de línguas em formação e falantes nativos dessas línguas, se caracterize como uma importante oportunidade de construções ou de transformações identitárias para esses professores. Ao entrarem em contato com esses nativos, de contextos 
culturais diversos (ou de diferentes linguascultura), nem sempre com prestígio social, os professores em formação têm a oportunidade de quebrar estereótipos e compreender que toda linguacultura é legítima e tem seu valor; que nenhuma é melhor ou pior que outra são apenas diferentes.

\section{$O$ caso do inglês}

A globalização, modernista e pós-moderna, deu ao inglês o status de língua franca - uma língua de comunicação entre os povos em prol da ciência e da tecnologia. Com o advento da internet, em especial, esse status ganhou força, uma vez que é a língua que mais possibilita e/ou facilita a interação entre as pessoas, independentemente de fronteiras geográficas. Mas que inglês é esse? O que significa ser uma língua franca, especialmente para aqueles que buscam aprendê-la para "comunicar-se com o mundo"? Acreditamos que não seja a mesma linguacultura tida como global (que na verdade não é única, mas várias) presente no "translinguajar" de falantes que a utilizam no seu dia a dia, que a transformam conforme suas necessidades locais, ou seja, a usam glocalmente ${ }^{18}$, mas um "inglês imaginado e mítico", que conquistou o status de "língua superior" e acabou tornando-se uma commodity, um produto almejado, que seria um dos requisitos para a inserção dos cidadãos na sociedade global e, em particular, no Norte-global (WALESKO, 2019, p. 116). Segundo Jordão (2004, p. 5):

[...] o inglês ainda é percebido como língua de propriedade de países do Círculo Interior, acompanhada por um mantra carregado de superioridade cultural, histórica, moral, econômica, um mantra que nos apresenta a língua inglesa como a língua de culturas superiores, de culturas da metrópole, do conhecimento verdadeiramente científico e confiável.

Obviamente, "esse" ILF, entendido como uma variedade "imaginada e mítica" ou, como comumente referenciado ELF, tem também em seus míticos "falantes nativos" modelos de proficiência na língua, como discutido previamente neste texto. Holliday (2006 p. 6) nos lembra que os "falantes nativos" de inglês de países ocidentais (centrais, ou do Círculo Interior, como coloca Jordão) representariam tanto o inglês ideal quanto a metodologia ideal para seu ensino e fariam parte da ideologia chamada de "falar nativo" ou native-speakerism. Para ele, professores de inglês não nativos - Non-Native English

${ }^{18}$ Glocal: neologismo a partir das palavras global e local para referir-se à presença da dimensão local na cultura global (WALESKO, 2019, p. 115). 
Teachers (NNETs) - não seriam caracterizados como tendo os mesmos atributos de professores nativos: organizados, autônomos, críticos e autodeterminados, o que resulta em uma "descrença cultural" ou uma "não crença" na sua habilidade de ensinar a língua.

Considerando a perspectiva de inglês enquanto uma prática social translíngue (CANAGARAJAH, 2013), entendemos o ILF (ou ELF) como

[...] um espaço onde o inglês é utilizado com uma língua franca para a comunicação entre falantes nativos, entre nativos e não nativos e entre não nativos, de nações diversas e com "ingleses" diferentes, que, no seu translinguajar, criam, no momento da interação comunicativa, um novo inglês, com novas palavras e novas estruturas - que sirvam, talvez, para a efetivação da comunicação somente naquele espaçotempo ou que sejam repetidas por esses e outros falantes e acabem tornando-se parte da língua inglesa (ao menos a local). (WALESKO, 2019, p. 117-118).

Entretanto é esse o entendimento de ILF/ELF que ainda falta à maioria dos professores de inglês que não possuem o inglês como língua nativa - $80 \%$ do total de professores de inglês no mundo, segundo Richardson (2016) - para que revejam suas crenças e transformem suas identidades docentes. De acordo com Richardson, como professores de língua inglesa

[...] precisamos parar de pensar sobre eles e nós e começar a olhar para o profissionalismo como um continuum. No continuum podemos olhar para profissionais como sendo mais, ou menos preparados, entendidos, competentes, usuários proficientes de inglês. (RICHARDSON, 2016 apud WALESKO, 2019, p. 120. $)^{19}$

Nossas percepções sobre algumas experiências interculturais de interação entre professores-praticantes e falantes-nativos de inglês durante as edições do evento "Café Cultural", apresentadas e discutidas na próxima seção deste texto como situações que acreditamos marcantes e, possivelmente, (trans)formadoras de identidades desses professores, apontam para a relevância de oportunidades como essa na área de formação de professores de línguas.

\section{O IMPACTO DE EXPERIÊNCIAS INTERCULTURAIS DE INTERAÇÃO ENTRE PROFESSORES-PRATICANTES E FALANTES NATIVOS DE IN-}

\footnotetext{
${ }^{19}$ No original: "[...] we need to stop thinking about them and us and start looking at professionalism as a continuum. On the continuum we can look at professionals as being more or less prepared, knowledgeable, competent, proficient USERS of English.".
} 


\section{GLÊS NAS IDENTIDADES DOCENTES}

Como seres socioculturais, emocionais, múltiplos e complexos que somos, estamos em constante transformação, ou, como afirma Wenger (1998), em um "constante tornar-se". Através do diálogo com as experiências que vivenciamos, com as pessoas e com os meios com os quais interagimos, nossas identidades são formadas e transformadas, dia a dia, mesmo que não o percebamos, conscientemente. Podemos inclusive nos comparar com a língua/gem: viva e em contínua metamorfose nos contextos inter/culturais em que está inserida.

Partindo desses pressupostos, apresentamos nossas percepções sobre o impacto de experiências interculturais de interação entre professores-praticantes, dos cursos de língua inglesa do projeto IFA/FIVU e falantes nativos de inglês nas identidades dos docentes, à medida em que promoveram a quebra de estereótipos e a desmistificação de crenças.

As experiências a seguir relatadas e analisadas têm como cenário a observação de situações e discursos ao longo das atividades da área de inglês durante as edições do "Café Cultural" do projeto IFA/FIVU, das quais participamos como coordenadoras. As vivências, como são de um projeto de extensão e não de pesquisa, serão relatadas sem que sejam identificados os participantes, preservando o anonimato de suas identidades.

Entre elas, está uma pergunta realizada durante a roda de conversa de inglês da primeira edição do "Café Cultural" de 2018, da qual uma das autoras deste texto participava, como coordenadora, junto a cerca de doze docentes de inglês, seis professores-praticantes, um convidado intercambista da República do Gana (África Ocidental) e outros quatro estadunidenses. A pergunta, de uma das professoras em formação, foi direcionada ao convidado estrangeiro ganense, também professor de inglês em sua terra natal, logo depois de ele ter se apresentado, no "seu inglês": "Qual a língua oficial em seu país?" ("What's the official language in your country?"). O convidado sorriu e, levantando os ombros num gesto de surpresa disse: "É inglês, claro!" ("It's English, of course!"). Percebemos, nessa situação, o quanto essa professora (e pode se estender a uma parcela significativa dos outros professores de inglês) acredita que há "um inglês" ou algumas variedades do inglês legitimadas e, portanto, a serem ensinadas como uma língua estrangeira ou adicional. Muito mais do que a falta de conhecimento sobre o país Gana (ex-colônia britânica), percebemos que a pergunta partiu da observação do inglês falado pelo visitante, em especial por seu sotaque, muito diferente do "inglês imaginado como americano ou britânico", que a maioria dos cursos de idiomas e livros didáticos se propõe a ensinar no Brasil. É importante ressaltar que o convidado ganense, 
como professor de inglês, se preocupou em comentar que falava também outra língua local e inclusive escreveu o nome dessa língua no quadro. Em seguida, um aluno participante perguntou onde, então, ele aprendeu inglês, talvez acreditando que ele tivesse o inglês como uma segunda língua, além da local, materna, usada em família. O professor ganense, mais uma vez em tom de surpresa respondeu que não sabia, pois falava inglês desde pequeno em todo lugar: na escola, em casa etc., ou seja, o inglês é também sua língua materna, embora provavelmente já muito distante do inglês que muitos consideram, no Brasil, como "inglês britânico". Percebemos o quão significativa essa interação intercultural com o falante nativo de inglês de Gana (que não é considerado um país do Norte-global) foi para os professores de inglês presentes (bem como deve ter sido para os demais participantes); para muitos um momento de reflexão crítica sobre suas crenças e/ou sobre o que aprenderam, estereotipadamente, que seja o inglês que deva ser ensinado e validado.

Em uma das aulas da graduação, logo após o evento, relembramos a situação com os professores-praticantes e eles enfatizaram o quanto somos preconceituosos e validamos, em nossas aulas, ideologias que, além de discriminatórias, nos colocam como inferiores ou impostores enquanto falantes do inglês que temos (assim como discriminamos o inglês do professor ganense) e o quanto precisamos reformular nossas crenças e promover, em sala de aula, um ensino intercultural, trazendo diferentes "ingleses", utilizados em diferentes contextos culturais, sejam eles diferentes nações ou diferentes espaços ou grupos sociais, dentro de uma mesma nação.

Uma outra experiência intercultural vivenciada no evento de 2017 durante a apresentação inicial de oito falantes nativos de inglês, originários de diferentes regiões dos Estados Unidos, foi o comentário de um dos professores-praticantes, entre cerca de vinte participantes presentes, dizendo que pensou que, pelo seu "jeito de falar", um deles (do Arizona) não fosse americano. Podemos inferir, a partir desse discurso, que há um estereótipo em relação ao inglês falado naquele país, como se fosse único, demonstrando a crença de que línguas-nação enquanto sistemas fixos existem e podem ser ensinadas e aprendidas. Na ocasião, eles responderam perguntas sobre assuntos diversos e foi interessante como, mesmo tendo o mesmo país como terra natal e a mesma língua materna, interagiam entre si reagindo com surpresa a colocações culturais como, por exemplo, sobre culinária ou festas típicas de suas regiões de origem e palavras a esses assuntos relacionadas, desconhecidas ou estereotipadas entre eles mesmos. Isso demonstra que, embora todos tivessem a mesma nacionalidade, suas linguascultura se diversificavam, o que aponta, mais uma vez, para a percepção de que precisamos, como 
professores de língua inglesa, questionar a existência de modelos de inglês ou modelos culturais a serem aprendidos e ensinados e que é impossível, mesmo dentro de um mesmo Estado-nação, que uma pessoa conheça as linguascultura de todos os contextos culturais utilizadas por todos os seus falantes. Essa reflexão também se aplica ao ensinoaprendizagem de outras línguas.

Devido à pandemia de Covid-19 que levou à suspensão das atividades presenciais na UFPR, os cursos de línguas do projeto FIVU foram ofertados apenas na modalidade remota e em menor número, pois muitos alunos (tanto os que cursavam os módulos, quanto os licenciandos, que ministravam as aulas) declararam impossibilidades ou dificuldades para estudar ou trabalhar online: alguns por falta de equipamentos ou internet em casa; vários precisaram deixar a capital e retornar para a casa dos pais e parentes em suas cidades-natal (ou por falta de condições financeiras para se manter ou para assistilos, já que decretos municipais proibiram a entrada de idosos em vários estabelecimentos comerciais); outros começaram a trabalhar no horário de aulas da universidade já que a família havia perdido os empregos ou tido sua renda reduzida e outros, ainda, por questões de doença. Assim, o evento "Café Cultural" de 2020 foi promovido remotamente apenas na área de língua inglesa uma vez que os cursos ofertados em outras línguas ou já haviam sido finalizados ou ainda iniciariam suas atividades.

O evento, chamado em inglês de Intercultural Café, foi realizado na plataforma institucional Teams da UFPR e envolveu a coordenadora (uma das autoras deste texto), duas licenciandas bolsistas, oito professores-praticantes, oito alunos do Curso de inglês - módulo 3/2020 (modalidade remota) e quatro falantes nativos estadunidenses, sendo duas participantes do estado de Ohio, um do Arizona e um da Virgínia. ${ }^{20}$ Após a abertura do evento e a apresentação pessoal de cada um dos convidados estrangeiros para o grande grupo, os participantes foram divididos em subgrupos na plataforma e, a cada dez minutos, deveriam conversar em inglês sobre um tema estipulado pelo grupo de organizadores (coordenação e bolsistas), relacionando-o a seu contexto cultural no momento da pandemia pela qual passávamos. Assim que todos os grupos discutissem o tema, o falante nativo convidado sairia do grupo onde se encontrava movendo-se (virtualmente e "acompanhado" por um professor-praticante do curso) para um novo grupo para discutir um novo tema, e assim sucessivamente. Durante a discussão do

\footnotetext{
${ }^{20}$ Embora o uso de aplicativos e plataformas digitais de comunicação facilitem a interação de pessoas que se encontram fisicamente em locais diversos, transpondo barreiras geográficas, a questão do fuso horário precisou ser considerada para o evento remoto e foi a principal causa da impossibilidade para que falantes nativos de inglês de alguns países (especialmente da Europa) pudessem participar.
}

Revista X, v. 16, n. 4, p. 1120-1142, 2021. 
primeiro tema, "education" (educação), uma das questões direcionadas à participante estrangeira foi, após relato da situação de dificuldades dos estudantes brasileiros, se todos os alunos de escolas públicas americanas teriam condições de estudar remotamente durante a pandemia, já que os Estados Unidos é tido, pela maioria dos brasileiros, como um país rico. Para a surpresa da participante, a resposta da convidada, que atua na equipe pedagógica do distrito escolar de Olentangy, em Ohio (EUA) foi que cerca de $40 \%$ dos americanos sequer têm acesso à internet em casa e que o estado, onde vive, recebeu milhares de famílias de refugiados ao longo dos últimos anos, cujos filhos estudam em escolas públicas, e que também tiveram muita dificuldade em termos de trabalho em decorrência da pandemia. Acreditamos que a surpresa, expressada com um "Wow!" se deva por conta do estereótipo cultural criado em torno dos Estados Unidos como um país sem problemas sociais, onde todos têm acesso à educação de qualidade, em especial na escola básica, que é quase que em sua totalidade pública. Percebemos, com essa experiência intercultural bastante glocalizada da ocasião, que o diálogo entre culturas se faz muito necessário na formação do aprendiz de uma outra língua e, principalmente, na formação de professores, uma vez que, para muito além do código escrito e falado, ensinam uma linguacultura que não é melhor nem pior que a materna, sua ou a de seus alunos, sendo assim responsáveis pela formação ética e cidadã de pessoas que exercerão profissões diversas, diretamente interagindo e agindo na sociedade em que vivemos.

\section{CONSIDERAÇÕES FINAIS}

Este artigo buscou discutir o impacto, em relação à formação e transformação de identidades docentes, de interações interculturais entre professores de línguas em formação e falantes nativos, tendo como cenário o evento "Café Cultural", do projeto de extensão IFA/FIVU e, mais especificamente, experiências das quais fizemos parte durante as interações ocorridas na área de língua inglesa, ao longo das edições do evento, tanto presenciais, entre 2017 e 2019, quanto remota, em 2020. Certamente, experiências similares ou outras ocorridas nas edições do evento "Café Cultural", nas interações que promoveram discussões interculturais entre nativos de outras línguas ensinadas no projeto IFA/FIVU e os participantes brasileiros que as estudam, poderiam complementar e/ou aprofundar nossas reflexões neste artigo. Apesar de nos limitarmos apenas às experiências da área de inglês, por terem sido as que vivenciamos, acreditamos que nossas análises e discussões também possam ser estendidas à formação de professores de outras línguas.

Acreditamos que eventos de extensão como esse são, além de oportunidades de integração social e interação cultural, ações imprescindíveis para a formação Revista X, v. 16, n. 4, p. 1120-1142, 2021. 
crítico-reflexiva de professores de línguas, uma vez que, além de desmistificar crenças relacionadas a falantes nativos das línguas ensinadas, promovendo o desenvolvimento de uma competência intercultural docente em relação à língua que ensinam-aprendem, também estimulam o desenvolvimento de uma consciência cidadã mais inclusiva e menos discriminatória a partir do contato com outras culturas/linguascultura.

Esse desenvolvimento também foi estimulado durante edições do evento no mês de junho de 2017 e de 2018 em uma campanha do agasalho para auxiliar alunos intercambistas com poucos recursos financeiros (alguns em situação de refugiados em nosso país), em especial os originários de países africanos ou da América Central, em geral de clima bastante quente e muito diferente do rigoroso frio do inverno típico de Curitiba. A campanha oportunizou aos integrantes dos cursos das línguas ofertadas pelo projeto, participantes do evento, conhecerem um pouco sobre quem seriam seus interlocutores estrangeiros e promoveu um senso de afetividade entre as pessoas, o que influenciou positivamente tanto as interações entre eles quanto as reflexões dos licenciandos em formação sobre cidadania e inclusão social, as quais também fazem parte de suas identidades docentes. Em outras palavras, essa ação da Campanha do Agasalho acabou tendo um caráter muito mais do que assistencial: foi uma ação transformadora de crenças e, portanto, formadora e transformadora de identidades.

Além disso, o evento "Café Cultural" pode ser compreendido como uma oportunidade de inclusão social para muitos dos intercambistas que circulam na universidade e no CELIN-UFPR, em especial para os que são muitas vezes discriminados, dentro e fora da universidade, por questões de raça, cor e/ou religião. Como observou uma professora-praticante de inglês durante a organização de uma das edições presenciais do evento, muitos intercambistas são vistos em pequenos grupos no Restaurante Universitário (RU) e ninguém "de fora" toma qualquer iniciativa para conversar com eles - em especial com os negros. Ou seja, não apenas a oportunidade de interagir com falantes nativos de outras culturas na língua estudada motivou a participação no evento, mas também sentimentos relacionados à solidariedade, empatia, respeito pelas diferenças e inclusão, essenciais na formação cidadã dos indivíduos.

Portanto as atividades realizadas no projeto de extensão como um todo e durante as atividades de todas as edições do evento (a preparação para interagir com falantes nativos, as rodas de conversa, o café Tandem e a Campanha do Agasalho) impactaram positivamente todos os envolvidos, em especial os professores-formadores e os professores-praticantes que, em um processo de formação docente críticoreflexiva, tiveram a oportunidade de melhor compreender que o papel do professor 
de línguas do século XXI pode ir muito além do ensinar uma língua em sala de aula nos termos tradicionais de concepção de língua como código, desvinculada de contextos socioculturais, e do que seja ensinar enquanto transmitir conhecimento. $\mathrm{Ou}$ seja, os professores tiveram a oportunidade de compreender seu papel social para o desenvolvimento da noção de cidadania simbólica, que, segundo Picanço (2012, p.116), sendo "diretamente relacionada com questões éticas, contraria ao relativismo cultural que promove a dominação cultural e socioeconômica".

Além disso, o evento contribuiu para a formação intercultural dos professores envolvidos: não apenas os professores-praticantes, licenciandos em formação inicial, mas também os professores-formadores, em processo de formação continuada nas próprias ações de formação.

Assim, ressaltamos a importância de promovermos, nas propostas de formação de professores de línguas, oportunidades de diálogo intercultural com falantes originários de contextos diversos, como as que têm acontecido ao longo das edições do evento de extensão "Café Cultural" do projeto IFA/FIVU. Esses falantes não necessariamente precisam ter a língua-alvo como nativa/materna, mas podem tê-la como segunda língua ou língua adicional, bem como sua origem pode ser de países diversos. ${ }^{21}$ Além disso, sugerimos que essas oportunidades sejam pensadas em torno de prazeres como o de compartilhar um café e/outras delícias que, certamente, influenciam nossas memórias afetivas e promovem aprendizagens significativas que acabarão tornando-se parte de nossas crenças enquanto docentes e, por sua vez, serão incorporadas em nossas identidades, profissionais e pessoais, sendo retomadas ao longo de nossas práticas pedagógicas na caminhada enquanto professores de línguas.

\section{REFERÊNCIAS}

BARCELOS, A. M. F. Cognição de professores e alunos: tendências recentes na pesquisa de crenças sobre ensino e aprendizagem de línguas. In: BARCELOS, A. M. F.; VIEIRAABRAHÃO, M. H. (org.). Crenças e ensino de línguas: foco no professor, no aluno e na formação de professores. Campinas: Pontes, 2006, p. 15- 41.

\footnotetext{
${ }^{21}$ A participação de uma falante de inglês árabe, bem como a de um coreano, foi uma experiência intercultural enriquecedora para os participantes de uma roda de conversa realizada no evento em 2018.
}

Revista X, v. 16, n. 4, p. 1120-1142, 2021. 
BARCELOS, A. M. F. Crenças sobre a aprendizagem de línguas, linguística aplicada e ensino de línguas. Linguagem e Ensino, Pelotas, v. 7, n. 1, p. 123-156, 2004.

BARCELOS, A. M. F. Researching beliefs about SLA: a critical review. In: KALAJA, P.; BARCELOS, A. M. F. Beliefs about SLA: new research approaches. Netherlands: Kluwer Academic Publishers, 2008.

BERNAT, E. Towards a pedagogy of empowerment: the case of "Impostor Syndrome" among pre-service non-native speaker teachers in TESOL. ELTED, v. 11, p. 1-8, 2008.

CANAGARAJAH, A. S. Translingual practice: global Englishes and cosmopolitan relations. New York: Routledge, 2013.

CANAGARAJAH, A. S. Agency and power in intercultural communication: negotiating English in translocal spaces. Language and intercultural communication, v. 13, n. 2, p. 202-224, 2014a.

CANAGARAJAH, A. S. In search of a new paradigm for teaching English as an international language. TESOL Journal, v. 5, n. 4, p. 767-785, 2014 b.

CANAGARAJAH, A. S. Translingual orientations and language teaching. Curso de Extensão. Universidade Federal do Paraná, Curitiba, 1 a 3 ago. 2017.

CARNEIRO, L.; CARNEIRO, H. Comida e sociedade: uma história da alimentação. Rio de Janeiro: Campus; 2003.

COOK, V. J. Going beyond the native speaker in language teaching. TESOL Quarterly, v. 33, n. 2, p. 185-209, 1999.

GARCÍA, O; WEI, L. The translanguaging turn and its impact. In: GARCÍA, O.; WEI, L. Translanguaging: language, bilingualism and education. Nova York: Palgrave MacMillan, 2014.

GIMENEZ, T.; CALVO, L. C. S.; EL KADRI, M. S. (org.). Inglês como língua franca: ensino-aprendizagem e formação de professores. v. 14. Campinas: Pontes, 2011.

HOLLIDAY, A. Native speakerism. ELT Journal, v. 60, n. 4, p. 385-387, out. 2006.

JENKINS, J. Repositioning English and multilingualism in English as a lingua franca. De Gruyter. Englishes in Practice, v. 2, n. 3, p. 49-85, 2015. 
JORDÃO, C. M. A língua inglesa como "commodity": direito ou obrigação de todos? In: CONGRESSO LUSO-AFRO-BRASILEIRO DE CIÊNCIAS SOCIAIS, 8. Coimbra, set. de 2004. Disponível em: http://www.ces.uc.pt/lab2004/inscricao/pdfs/grupodiscussao32/ ClarissaJordao.pdf. Acesso em: 10 fev. 2021.

JORDÃO, C. M. A posição de professor de inglês no Brasil: hibridismo, identidade e agência. Letras \& Letras, v. 26, p. 427-442, 2010.

JORDÃO, C. M. Desvincular o inglês do imperialismo: hibridismo e agência no inglês como língua internacional. Versalete, v. 1, p. 278, 2013.

JORDÃO, C. M.; MARQUES, A. N. English as a lingua franca and critical literacy in teacher education: shaking off some "good old" habits. In: GIMENEZ, T.; EL KADRI, M. S.; CALVO, L. C. S. (ed.). English as a lingua franca in teacher education. A Brazilian perspective. Berlin/Boston: De Gruyter Mouton, 2017.

KRAMSCH, C. J. Imposture: A late modern notion in poststructuralist SLA research. Oxford University Press: Applied Linguistics, v. 33, n. 5 p. 483-502, 2012.

KUMARAVADIVELU, B. Individual identity, cultural globalization, and teaching English as an international language: The case for an epistemic break. In: ALSAGOFF, L.; MCKAY, S. L.; HU, G.; RENANDYA, W. A. (ed.). Principles and practices for teaching English as an international language. New York: Routledge, 2012.

LEE, J. W. The politics of translingualism. Routledge: New York, 2018.

LIU, J. Nonnative-English-speaking professionals in TESOL. TESOL Quarterly, v. 33, n. 1, p. 85-102, 1999.

PENNYCOOK, A. The myth of English as an international language. In: MAKONI, S.; PENNYCOOK, A. (ed.). Desinventing and reconstructing languages. USA: Multilingual Matters, 2007.

PICANÇO, D. C. de L. Aspectos políticos, discursivos e subjetivos da interculturalidade na formação do professor de espanhol como LE. Eutomia, Recife, v. 10, n. 1, p. 111-132, dez. 2012.

PINTO, T. dos S. Raízes do café no Brasil. Brasil Escola. Disponível em: https:// brasilescola.uol.com.br/historia/o-cafe-no-brasil-suas-origens.htm. Acesso em: 30 out. 2020 . 
RAJAGOPALAN, K. Non-native speaker teachers of English and their anxieties: ingredients for an experiment in action research. In: LLURDA, E. (ed.). Non-native language teachers: Perceptions, challenges and contributions to the profession. New York: Springer, 2005.

RICHARDSON, S. The native factor: the haves and the have-nots. Plenary. IATEFL, BRITISH COUN CIL, BIRMINGHAM, 2016. Disponível em: http://teflequityadvocates. com/2016/04/20/the-native-factor-whats-next-aftersilvanarichardsons-iatefl-2016plenary/. Acesso em: 23 nov. 2018.

SIQUEIRA, D. S. P. English as a lingua franca and teacher education: critical educators for an intercultural world. In: GIMENEZ, T.; EL KADRI, M. S.; CALVO, L. C. S. (ed.). English as a lingua franca in teacher education: a Brazilian perspective. Berlin/Boston: De Gruyter Mouton, 2017.

VOLÓCHINOV, V. Marxismo e filosofia da linguagem: problemas fundamentais do método sociológico na ciência da linguagem. 1. São Paulo: Editora 34, 2017.

WALESKO, A. M. H. A interculturalidade no ensino comunicativo de língua estrangeira: um estudo em sala de aula com leitura em inglês. 2006. Dissertação (Mestrado em Letras). Universidade Federal do Paraná. Curitiba, 2006.

WALESKO, A. M. H. Formação inicial e o mito do "falante nativo": construções identitárias de professores de inglês em uma comunidade de prática. 2019. Tese (Doutorado em Letras). Universidade Federal do Paraná. Curitiba, 2019.

WENGER, E. Communities of practice: learning, meaning and identity. Cambridge: Cambridge University Press, 1998.

ZACCHI, V. Global Englishes, local histories. In: GIMENEZ, T.; EL KADRI, M. S.;

CALVO, L. C. S. (ed.). English as a lingua franca in teacher education: a Brazilian perspective. Berlin/Boston: De Gruyter Mouton, 2017.

Recebido em: 07 nov. 2020.

Aceito em: 13 dez. 2020. 